Article

\title{
A Novel Application of Electroactive Polyimide Doped with Gold Nanoparticles: As a Chemiresistor Sensor for Hydrogen Sulfide Gas
}

\author{
Lee Marvin G. Padua ${ }^{1}$, Jui-Ming Yeh ${ }^{2, *}$ and Karen S. Santiago ${ }^{3, *(\mathbb{D}}$ \\ 1 Department of Math and Physics, College of Science, University of Santo Tomas, Manila 1008, Philippines; \\ marb8402@gmail.com \\ 2 Department of Chemistry, Research and Development Center for membrane Technology, Center for \\ Nanotechnology, Chung Yuan Christian University, Zhongli, Taoyuan 32023, Taiwan \\ 3 Department of Chemistry, College of Science; Research Center for Natural and Applied Sciences, \\ University of Santo Tomas, Manila 1008, Philippines \\ * Correspondence: juiming@cycu.edu.tw (J.-M.Y.); kssantiago@ust.edu.ph (K.S.S.)
}

Received: 4 November 2019; Accepted: 20 November 2019; Published: 21 November 2019

check for updates

\begin{abstract}
This research paper presents a new application of electroactive polyimide doped with gold nanoparticles (PI/AuNPs) as a chemiresistor sensor for detecting hydrogen sulfide gas. The synthesis of PI/AuNPs was done in a simple 3-step process of polymerization using the as prepared amine-capped aniline trimer (ACAT), followed by imidization, and doping. Spectral analyses via FTIR, LC-MS and ${ }^{1} \mathrm{H}-\mathrm{NMR}$ confirmed the formation of amine-capped aniline trimer with a MW of $288 \mathrm{~g} \mathrm{~mol}^{-1}$. Comparison of ACAT, BSAA, and PI FTIR spectra showed successful polymerization of the last, while XRD validated the incorporation of metal nanoparticles onto the polymer matrix, showing characteristic diffraction peaks corresponding to gold. Furthermore, TEM, and FE-SEM revealed the presence of well-dispersed Au nanoparticles with an average diameter of about $60 \mathrm{~nm}$. The electroactive PI/AuNPs-based sensor showed a sensitivity of $0.29 \% \mathrm{ppm}^{-1} \mathrm{H}_{2} \mathrm{~S}$ at a linear concentration range of 50 to $300 \mathrm{ppm} \mathrm{H}_{2} \mathrm{~S}(\mathrm{r}=0.9777)$. The theoretical limit of detection was found at $0.142 \mathrm{ppm}$ or $142 \mathrm{ppb} \mathrm{H}_{2} \mathrm{~S}$ gas. The sensor provided a stable response reading at an average response time of $43 \pm 5 \mathrm{~s}$, which was easily recovered after an average time of $99 \pm 5 \mathrm{~s}$. The sensor response was highly repeatable and reversible, with RSD values of $8.88 \%$, and $8.60 \%$, respectively. Compared with the performance of the conventional conducting polyaniline also doped with gold nanoparticles (PANI/AuNPs), the fabricated electroactive PI/AuNPs exhibited improved sensing performance making it a potential candidate in monitoring $\mathrm{H}_{2} \mathrm{~S}$ in the environment and for work-related safety.
\end{abstract}

Keywords: conducting polymers; metal nanoparticles; gas sensor; hydrogen sulfide gas

\section{Introduction}

Characterized by a pungent odor similar to the smell of rotten eggs, this colorless and flammable gas known as hydrogen sulfide $\left(\mathrm{H}_{2} \mathrm{~S}\right)$ is considered poisonous at certain concentrations. As reported in Occupational and Safety and Health Administration [1,2], inhaling $20 \mathrm{ppm} \mathrm{H}_{2} \mathrm{~S}$ may cause possible fatigue, loss of appetite, headache, irritability, poor memory, and dizziness. Depending on the length of exposure to $\mathrm{H}_{2} \mathrm{~S}$ gas, severe conditions may occur when exposed to higher concentrations. For example, prolonged exposure to $150 \mathrm{ppm}_{2} \mathrm{~S}$ gas could quickly paralyze the olfactory nerve disabling it from its capacity to recognize its presence. An hour of exposure to $700 \mathrm{ppm} \mathrm{H}_{2} \mathrm{~S}$ gas could seriously damage the eyes, cause rapid loss of consciousness, or worst lead to possible sudden death [3-6]. 
Commonly, hydrogen sulfide gas is released in high quantities during excavation of landfills or swamps [7,8], and in higher amounts during a volcanic activity [9-11]. Furthermore, $\mathrm{H}_{2} \mathrm{~S}$ gas is present in petrochemical reservoirs-in oil and natural gas wells, pipelines where unrefined petroleum is transported, and in refinery stations where $\mathrm{H}_{2} \mathrm{~S}$ is removed [12-14]. In the paper industry [15,16], and iron smelters [17], $\mathrm{H}_{2} \mathrm{~S}$ is a usual by-product. As $\mathrm{H}_{2} \mathrm{~S}$ gas is denser than air, it can easily accumulate in areas like mine tunnels [18], sewers [19], and manure tanks [20,21]. Due to the ubiquity of $\mathrm{H}_{2} \mathrm{~S}$ gas, and the possible danger this gas may cause, its detection is deemed highly important. However, the gas should not be directly perceived by the olfactory nose, nor should the level be closely assessed without the use of external devices.

There have been reports on the use of gas chromatography (GC) [22-24], infrared spectroscopy (IR) [25], ultraviolet spectroscopy (UV) [26-29], and fluorometry [30] in $\mathrm{H}_{2} \mathrm{~S}$ determination, but these techniques involved the use of relatively expensive bulky instrumentation, and required tedious sampling preparations. Alternatively, the use of sensors was also a subject of heightened interest due to the many modes of detection that could be explored, such as electrochemical [30-32], optical [33,34], piezoelectric $[35,36]$, and chemiresistive $[37,38]$. Sensors based on the chemiresistive mode was the simplest, operating based on the change in electrical resistance as the sensing material absorbs the gas analyte [39-43]. Metal oxide sensors (MOS) have been widely used in the construction of chemiresistive sensors of noxious gases due to their inexpensiveness and simplicity in both preparation and operation. These sensors also offer a wide array of detectable gases, hence expanding possible fields of applications. However, gas sensors fabricated using inorganic materials like metal oxides require operation at higher temperatures, as the high sensitivity of the said sensors is based on the high working temperature. This is often possible through the use of heated filament, and this entails the requirement of a higher amount of electricity to operate [44,45]. On the other hand, conducting polymers (CPs) also appear attractive as active elements in gas sensors. Compared with MOs, CPs present many advantages, such as high sensitivity, short response time, and room temperature operation. However, CPs offer low processability, and poor mechanical strength and chemical stability $[46,47]$. There have also been reports on the use of metal nanoparticles such as silver nanoparticles [26,48], and gold nanoclusters [30,49], but the detection is coupled to costly optical measurement devices.

This study, therefore, explored the use of combined electroactive polymers and gold nanoparticles to address issues encountered when these materials are used individually. Based on the literature survey conducted, this is the first time that electroactive polyimide decorated with gold nanoparticles has been used and developed for detecting trace levels of hydrogen sulfide gas at ambient room temperature. In the past, electroactive polyimide doped with gold nanoparticles was investigated for other applications such as electrochemical sensing of ascorbic acid [50]. Other studies of these combined materials focused on the effects of gold nanoparticles on polyimide in improving fluxes of the polymer for its possible nanofiltration application [51]. Most studies involving various uses dealt with EPI in different forms, while maximizing its inherent properties. Based on its redox properties, EPI was used as a recognition element in the fabrication of electrochemical sensors [52-55] and as an anticorrosion material [56-64]. Based on its doping and dedoping capability, EPI was also explored as a gas separation membrane [65], and as a smart material characterized for its switchable superhydrophobicity [66]. There have also been papers that investigated means to improve EPI's mechanical strength $[67,68]$ and thermal properties [69]. It is worthy of mentioning that the results obtained in this research showed that compared with the performance of the traditional conducting PANI/AuNPs, the fabricated electroactive PI/AuNPs exhibited improved sensing performance, making it a potential candidate in monitoring $\mathrm{H}_{2} \mathrm{~S}$ in the environment and for work-related safety. 


\section{Experimental}

\subsection{Chemicals and Equipment}

Aniline $(99.0 \%$, Fluka) was distilled under reduced pressure prior to use. Chemicals such as 4, 4'-diaminodiphenylamine sulfate hydrate (>97.0\%, TCI), 4, $4^{\prime}$-(4,4'-isopropylidene diphenoxy)-bis(phthalic anhydride) (BSAA, 97.0\%, Aldrich), gold(III)chloride trihydrate $\left(\mathrm{HAuCl}_{4} \cdot 3 \mathrm{H}_{2} \mathrm{O}\right.$, 99.99\%, Alfa Aesar) 1-methyl-2-pyrrolidone (NMP, 99.7\%, MACRON), N,N-dimethylacetamide (DMAc, 99.0\%, MACRON, and 99\%, Sigma-Aldrich, St. Louis, MO, USA), acetone (Ac, 99.5\%, J.T. Baker, New Jersey, USA), methanol (MeOH, 99.8\%, J.T. Baker), tetrahydrofuran (THF, 99.8\%, RCI Labscan, Bangkok, Thailand), cyclohexanone $(\mathrm{CH}, 100 \%$, J.T. Baker), dimethylformamide (DMF, 99.9\%, J.T. Baker), acetonitrile (ACN, 100\%, J.T. Baker) were used without further purification.

Infrared spectra were recorded using JASCO FT/IR-4100. To confirm presence of the Au nanoparticles, the samples were cut using a diamond knife to a 60-90 nm thick sections, and observed using a JEOL-200FX TEM (JEOL, Tokyo, Japan). The morphology of samples was recorded using scanning electron microscopy (SEM) (Hitachi S-2300). X-ray diffraction (XRD) analyses were recorded using a Philips X'pert Pro X-ray diffractometer. Electrochemical properties were investigated using a conventional three-electrode system connected to a VoltaLab 40 analytical voltammeter. ${ }^{1} \mathrm{H}$ NMR investigations were carried out using Bruker 300 spectrometer, referenced to internal standard of tetramethylsilane (TMS). DMSO was used as solvent. LC-MS further facilitated analysis of samples using Bruker Daltonics ion trap mass spectrometer (Model: Esquire 2000 with an Agilent ESI source (Model: G1607-6001, Leipzig, Germany).

A UNI-T UT71A multimeter with UT71A_B V3.00 software/Agilent 34410A desktop multimeter with Keysight BenchVue V 3.0 software (MatLab, CA, USA), was used in testing the gas sensing capability of the polymeric membranes.

\subsection{Synthesis and Characterization of PI and PI/AuNPs}

Amino-capped aniline trimer (ACAT) was prepared by following the procedure reported by Wei et al. Briefly, the synthesis of ACAT involved the use of ammonium persulfate to oxidize 2 equivalents of aniline and 1,4-phenylenediamine [70]. The success of ACAT preparation was confirmed by ${ }^{1} \mathrm{H} \mathrm{NMR}$ mass, LC-MS, and FT-IR spectroscopy.

The electroactive polyimide (PI) was synthesized using ACAT and BSAA. Solution A was prepared by dissolving BSAA $(0.52 \mathrm{~g}, 1 \mathrm{mmol})$ in $8.0 \mathrm{~g}$ of DMAc with continuous stirring for $30 \mathrm{~min}$ at room temperature. Solution B was prepared by dissolving ACAT $(0.29 \mathrm{~g}, 2 \mathrm{mmol})$ in $8.0 \mathrm{~g}$ of DMAc with continuous stirring for $30 \mathrm{~min}$ at room temperature. After stirring for $30 \mathrm{~min}$, solution $\mathrm{B}$ was added to solution $\mathrm{A}$, and mechanically stirred for $24 \mathrm{~h}$ to prepare a poly(amic acid) solution. The poly(amic acid)(PAA) was converted to polyimide(PI) by chemical imidization reaction. This reaction was done by adding acetic anhydride $(0.102 \mathrm{~g}, 1 \mathrm{mmol})$ and pyridine $(0.079 \mathrm{~g}, 1 \mathrm{mmol})$ to the solution, and refluxing for $3 \mathrm{~h}$ under nitrogen. Methanol $(250 \mathrm{~mL})$ was used to wash the PI and dried at $60{ }^{\circ} \mathrm{C}$ under vacuum for 1 day. The PI was characterized by ${ }^{1} \mathrm{H}$ NMR, LC-MS, FT-IR spectroscopy, X-ray diffraction.

The gold nanoparticle-doped electroactive polyimide (PI/AuNPs) samples were prepared by dissolving PI in DMAc, and adding aqueous $\mathrm{HAuCl}_{4}$ solution $(1 \mathrm{mM})$ at room temperature, then stirring for $6 \mathrm{~h}$. After the reaction, centrifugal filtration was done to collect the precipitate. Large volumes of distilled water were used to wash the residue. The PI/AuNPs were dried in a vacuum oven at $60^{\circ} \mathrm{C}$. The PI-AuNP was characterized using TEM, FT-SEM, and X-ray diffraction.

\subsection{Evaluation of Fabricated Sensors Toward $\mathrm{H}_{2} \mathrm{~S}$}

$\mathrm{H}_{2} \mathrm{~S}$ headspace generation. Hydrogen sulfide is generated in a reaction chamber by mixing $7.1 \mathrm{mg}$ ferrous sulfide $(\mathrm{FeS})$ and $10 \mathrm{~mL} 5 \mathrm{M}$ hydrocholoric acid $(\mathrm{HCl})$. This reaction produced $50 \mathrm{ppm}$ 
concentration of $\mathrm{H}_{2} \mathrm{~S}$ in a $55 \mathrm{~mL}$ sample chamber. The procedure was repeated to achieve 100,150, 200, 250, and $300 \mathrm{ppm} \mathrm{H}_{2} \mathrm{~S}$.

As illustrated in Figure 1a, the gas sensing set-up was composed of a nitrogen tank connected to an enclosed reaction chamber (left, $\mathrm{V}=55 \mathrm{~mL}$ ), where generation of hydrogen sulfide gas occurred. The generated $\mathrm{H}_{2} \mathrm{~S}$ gas was flushed into the sample chamber (middle, $\mathrm{V}=55 \mathrm{~mL}$ ) for determination using the fabricated sensor attached to a UNI-T multimeter. The resistance data obtained was recorded continuously using a computer. The gas exhausted from the sample chamber was bubbled in the third chamber containing water.

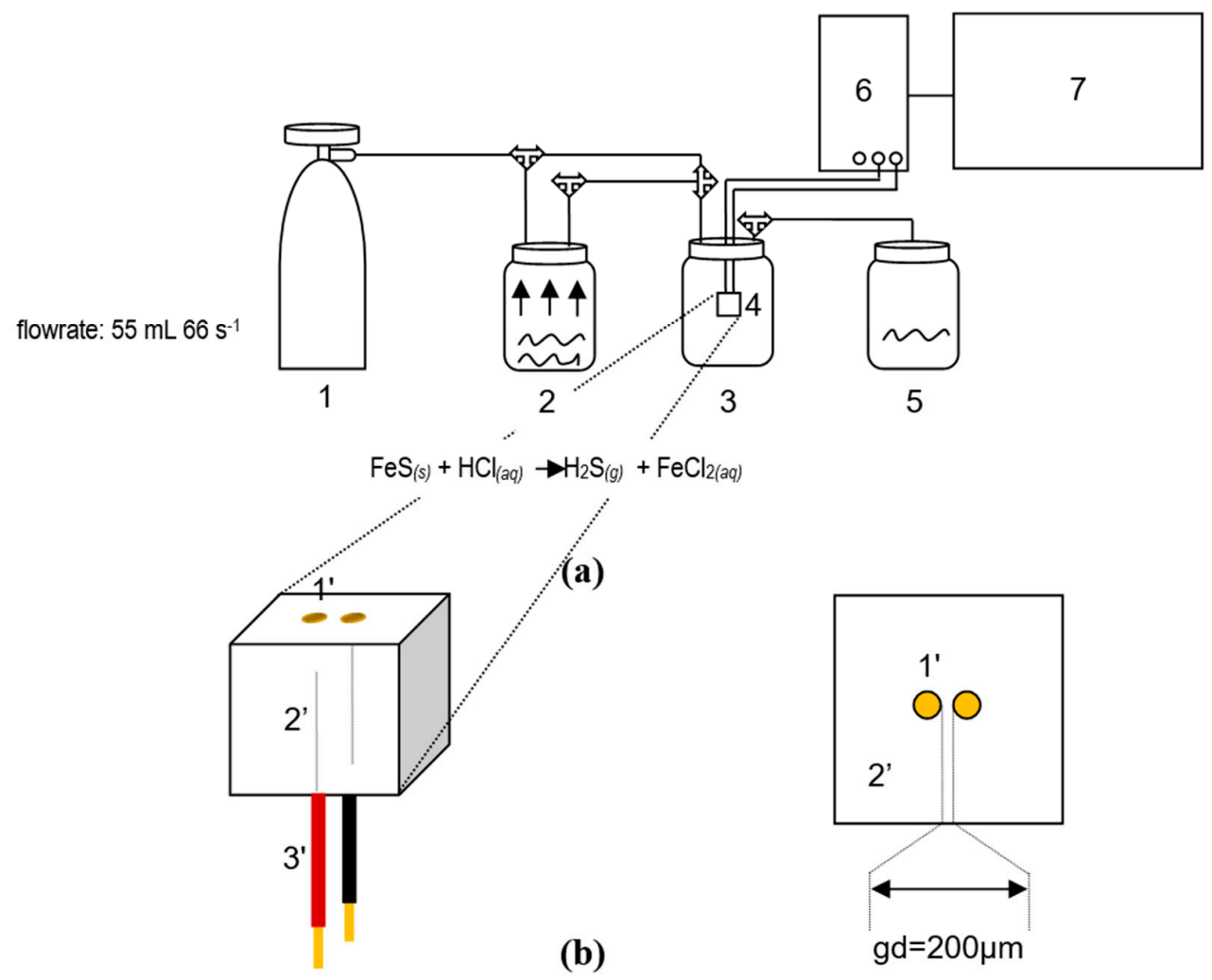

Figure 1. An illustration of the (a) gas sensing set-up: (1) $\mathrm{N}_{2}$ tank, (2) reaction chamber, (3) sample chamber, (4) PI/AuNPs-based $\mathrm{H}_{2} \mathrm{~S}$ gas chemiresistor sensor, (5) reservoir for exhausted gas, (6) multimeter, and (7) computer; and (b) sensor substrate configuration: left-side view, and right-top view (1') Au discs (end of Au wires), (2') Teflon block, and (3') insulated Cu wires.

Substrate preparation. The substrate (Figure $1 \mathrm{~b})$ is composed of gold wires (18 karats, $\varnothing=$ $0.5 \mathrm{~mm}, 1=0.5 \mathrm{~cm})$ soldered to polished copper wires $(\varnothing=0.5 \mathrm{~mm}, 1=2.5 \mathrm{~cm})$. A pair of soldered $\mathrm{Au}-\mathrm{Cu}$ wires, separated by a $200 \mu \mathrm{m}$ gap, was mounted into a custom made Teflon bar $(10 \mathrm{~mm} \times$ $10 \mathrm{~mm} \times 4 \mathrm{~mm}$ ). The wires were cleaned via ultrasonication in detergent solution for $15 \mathrm{~min}$. This step was immediately followed with washing of wires using water, acetone, methanol, water, and then dried. The wires were held in a sturdy and upright position by applying a cyanoacrylate adhesive (Mighty Bond ${ }^{\mathrm{TM}}$ by Pioneer (®)adhesives). The exposed Au ends, which served as the substrate, were subsequently polished with high grade of abrasive paper (1200 grit) and pad with aluminum slurry $(\varnothing=3 \mu \mathrm{m})$. The polished electrodes were then washed with methanol, sonicated in ultrapure water for 5 minutes, and dried.

Sensor performance evaluation. The sensor performance was evaluated based on sensitivity, linearity, linear concentration range, limit of detection, dynamic response and recovery characteristics, repeatability and reproducibility, and selectivity. 


\section{Results and Discussion}

\subsection{Synthesis and Characterization of PI-Based Materials}

\subsubsection{Synthesis of electroactive polyimide-based materials}

The ACAT was synthesized by the oxidative coupling of 4-4'-diaminodiphenylamine and aniline monomer by the addition of ammonium persulfate as the oxidant (Scheme 1). The synthesized ACAT was then subjected to chemical polymerization with the aid of BSAA, resulting in the formation of poly(amic acid). Finally, the poly(amic acid) underwent chemical imidization by acetic anhydride and pyridine to form the final product, electroactive polyimide.

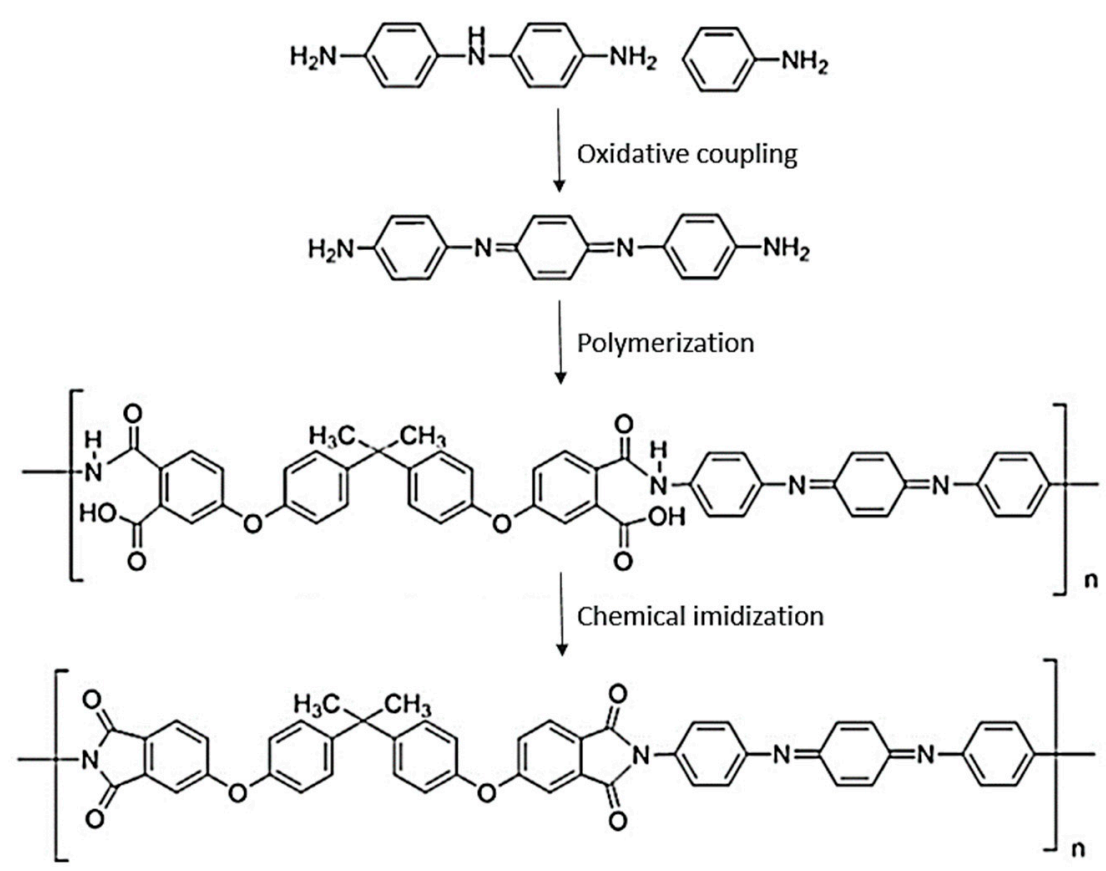

Scheme 1. Proposed mechanism for the synthesis of electroactive polyimide.

Scheme 2, adapted from the work of Ji et al. [50], shows the proposed mechanism of the formation of electroactive PI/AuNPs by doping gold nanoparticles onto the synthesized PI, with the aid of dimethyl acetamide and ethyl acetate solvents.

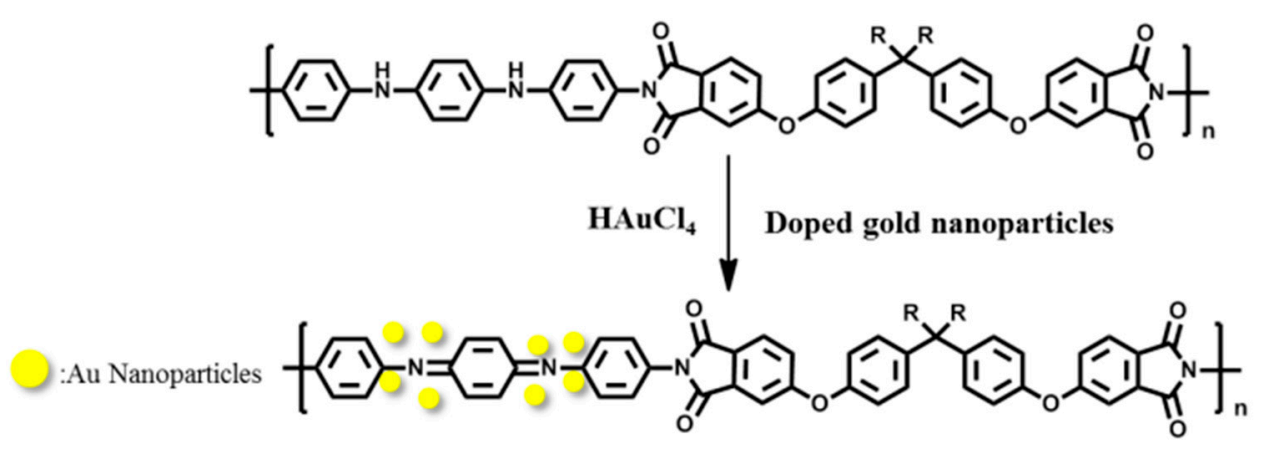

Scheme 2. Proposed mechanism for the synthesis of gold nanoparticle-doped electroactive polyimide.

\subsubsection{Structural and Morphological Characterization}

Figure 2a,b shows the LC-MS spectra of the synthesized ACAT. It can be seen that the maximum intensity in the $\mathrm{MS}^{+}$spectrum occurred at $289.1 \mathrm{~m} / \mathrm{z}$, while the maximum in the $\mathrm{MS}^{-}$spectrum occurred 
at $286.9 \mathrm{~m} / \mathrm{z}$. These results suggest that the synthesized powder is ACAT. In theory, the molecular weight of ACAT is $288 \mathrm{~g} \mathrm{~mol}^{-1}$. The peak shifted by $+/-1$ which could be attributed to $\mathrm{H}$.
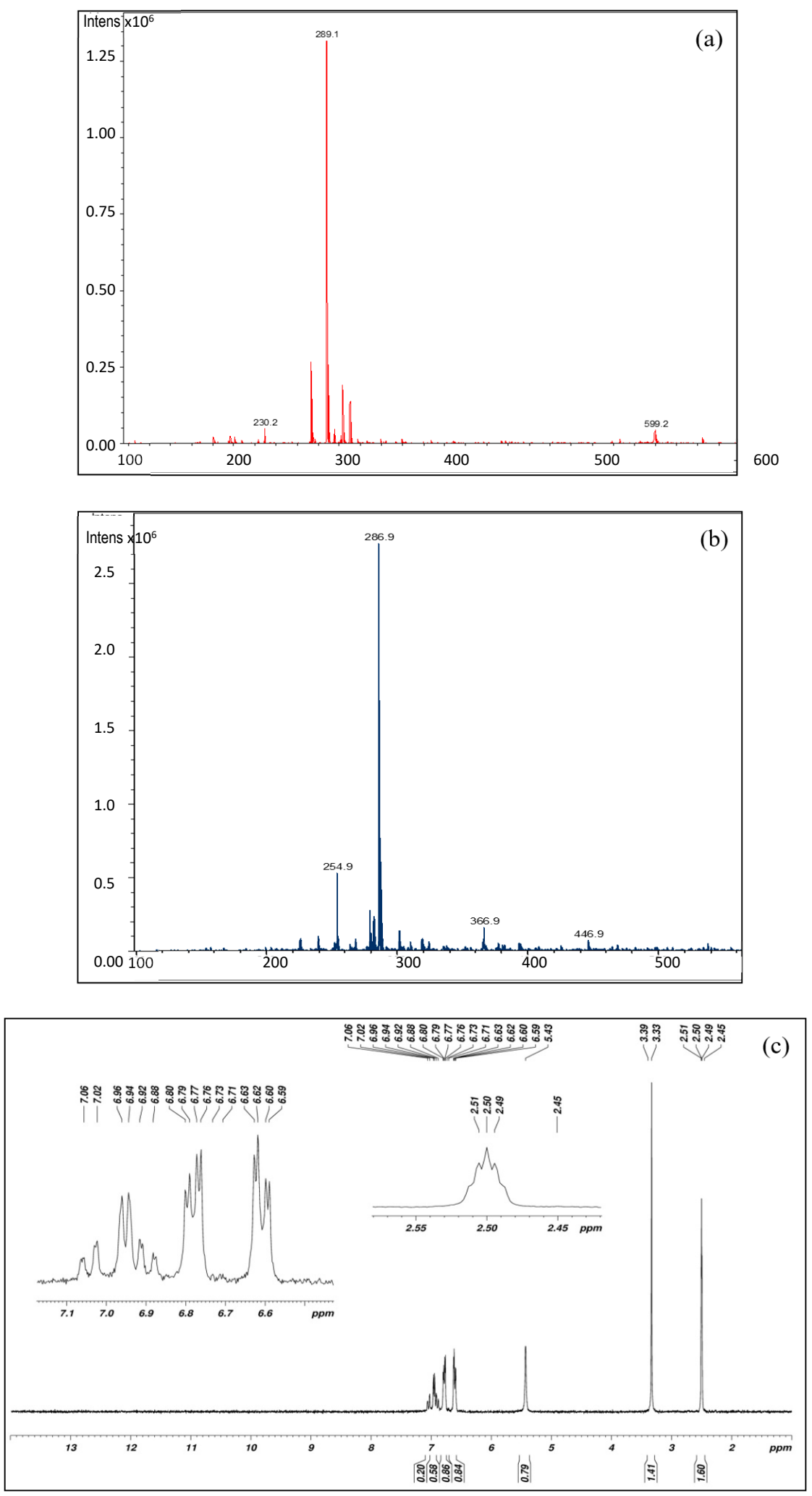

Figure 2. LC-MS spectra (a) $\mathrm{MS}^{+}$mode and (b) $\mathrm{MS}^{-}$mode, and (c) ${ }^{1} \mathrm{H}-\mathrm{NMR}$ spectrum of the synthesized ACAT powder. 
Further confirmation of the successful synthesis of ACAT using ${ }^{1} \mathrm{H}-\mathrm{NMR}$ spectroscopy was done. The sample used was prepared by dissolving a small amount of the synthesized ACAT in dimethylsulfoxide- $\mathrm{d}_{6}\left(\left(\mathrm{CD}_{3}\right)_{2} \mathrm{SO}\right)$. Figure $2 \mathrm{c}$ shows the spectrum obtained from the analysis.

The results show that PI (Figure 3c) has the same characteristic peaks with ACAT (Figure 3a) at 1504 and $1596 \mathrm{~cm}^{-1}$. The characteristic peaks at 1504 and $1596 \mathrm{~cm}^{-1}$ may be due to the vibration bands of benzenoid rings and quinoid rings of ACAT, respectively. At $1750 \mathrm{~cm}^{-1}$, PI (Figure 3c) and BSAA (Figure $3 b$ ) have characteristic peaks referring to the vibration bands of BSAA's $C=O$ groups. Based on the overall spectra, the synthesis of PI was successfully achieved.

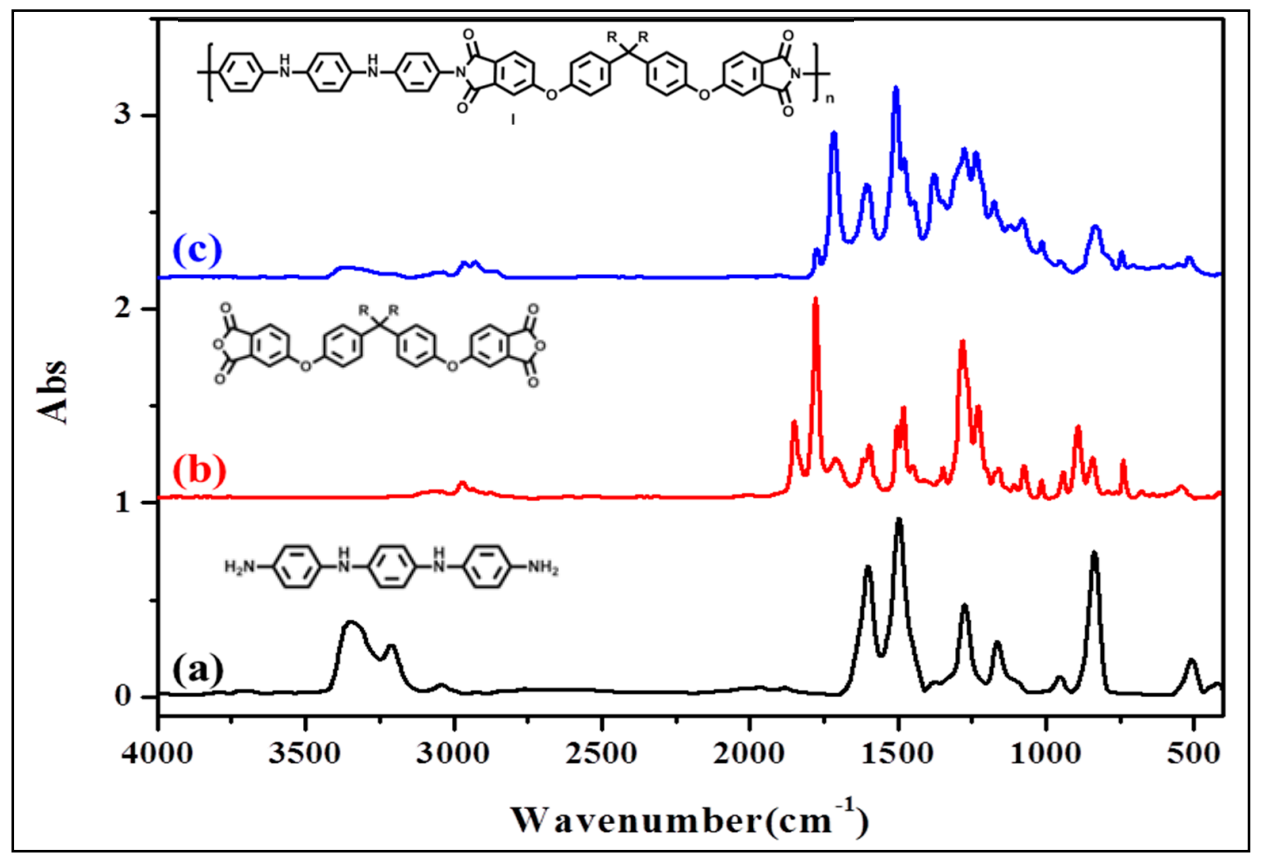

Figure 3. FTIR spectra of (a) synthesized ACAT, (b) BSAA, (c) synthesized electroactive PI.

TEM and FE-SEM micrographs reveal the presence of well-dispersed Au nanoparticles with an average diameter of about $60 \mathrm{~nm}$, as shown in Figure 4.

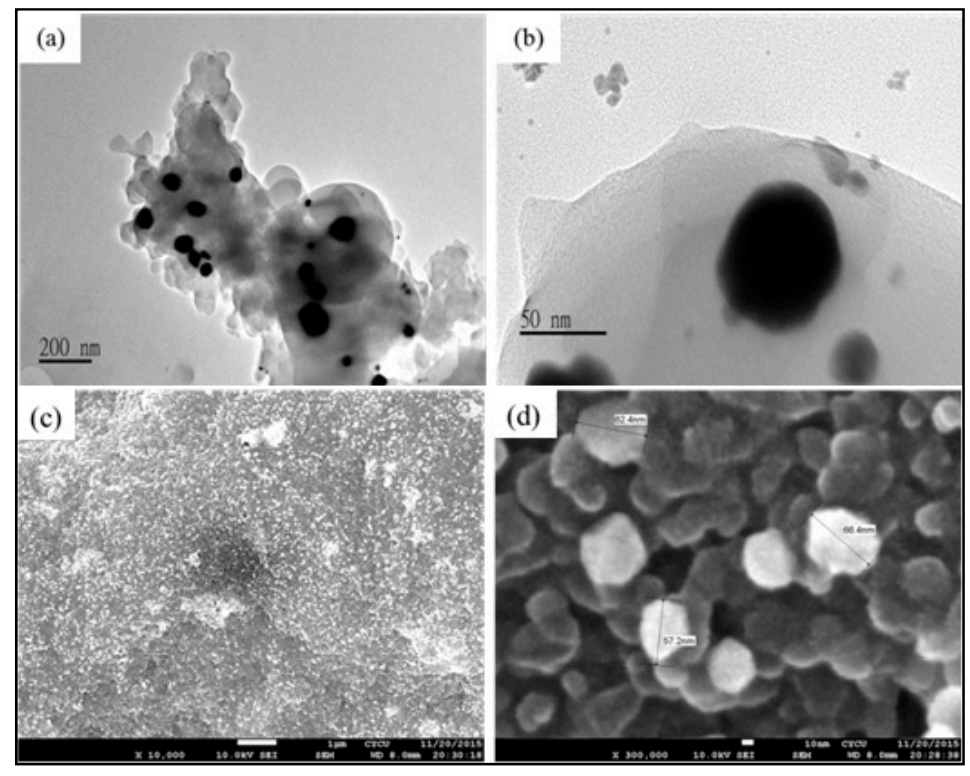

Figure 4. (a,b) TEM, and (c,d) FE-SEM images of the synthesized electroactive PI/AuNPs. 
The diffractogram in Figure 5 a shows a broad peak between $15-20^{\circ}(2 \theta)$, which can be attributed to the semi-crystalline nature of the PI sample, having periodic parallel polymer chains. The diffractogram of the PI/AuNPs (Figure $5 \mathrm{~b}$ ) show the characteristic peaks of gold occurring at $38.01^{\circ}, 43.96^{\circ}, 64.50^{\circ}$, and $77.42^{\circ}(2 \theta)$, corresponding to reflections from the planes, (111), (200), (220), and (311) [71]. The prominent diffraction at $38.01^{\circ}$ revealed that zero valent gold grew and mostly fixed in the direction (111). This behavior also signifies the formation of pure gold nanocrystals [72].

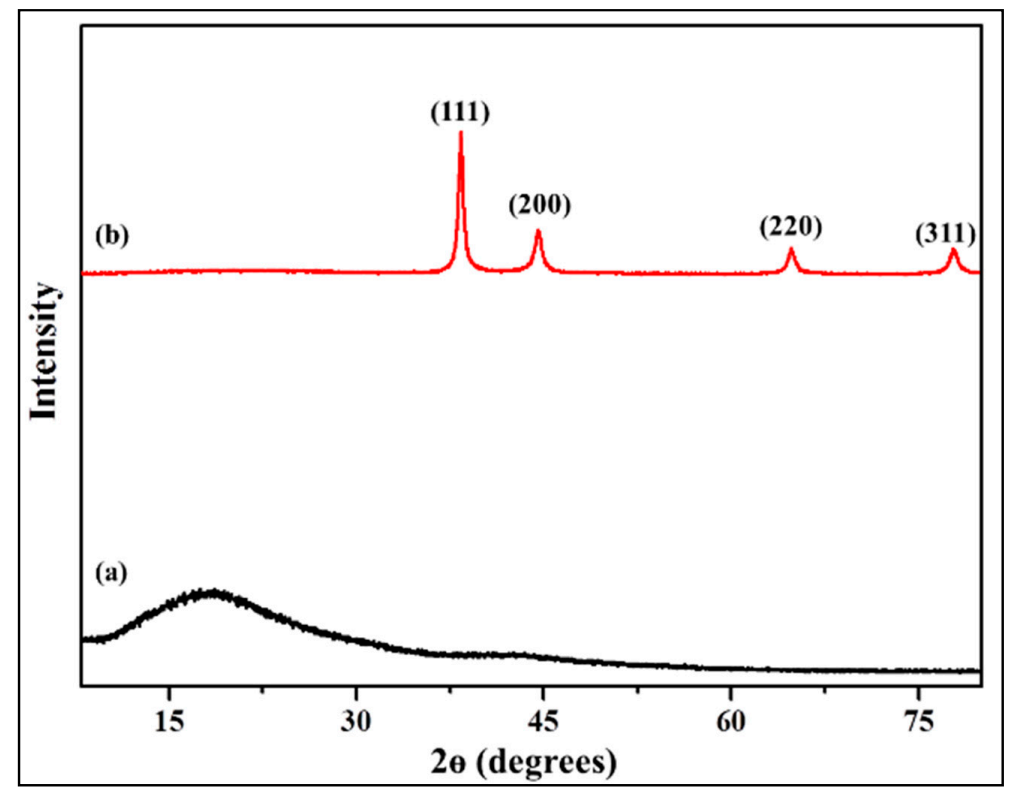

Figure 5. XRD pattern of electroactive (a) PI and (b) PI/AuNPs.

\subsection{Evaluation of the Sensor's Performance}

Sensitivity, linearity, and limit of detection. Shown in Figure 6a is the calibration curve constructed based in the performance of electroactive polyimide doped with gold nanoparticles (PI/AuNPs) towards increasing concentration of hydrogen sulfide gas. Responses were reported as $\left(\Delta R / R_{0}\right) \times 100 \% ; \Delta R=/ R_{\mathrm{g}}-R_{0} /$, where $R_{\mathrm{g}}$ is the resistance of the chemiresistor gas sensor and $R_{0}$ refers to baseline resistance. The sensor presented a sensitivity of $0.29 \% \mathrm{ppm}^{-1} \mathrm{H}_{2} \mathrm{~S}$ gas and a linearity of 0.9777 at a dynamic linear concentration range of 50 to $300 \mathrm{ppm} \mathrm{H}_{2} \mathrm{~S}$ gas. The theoretical detection limit was found to be $0.142 \mathrm{ppm}$ or $142 \mathrm{ppb} \mathrm{H}_{2} \mathrm{~S}$, estimated according to the least-square method of fitting in the linear regime.

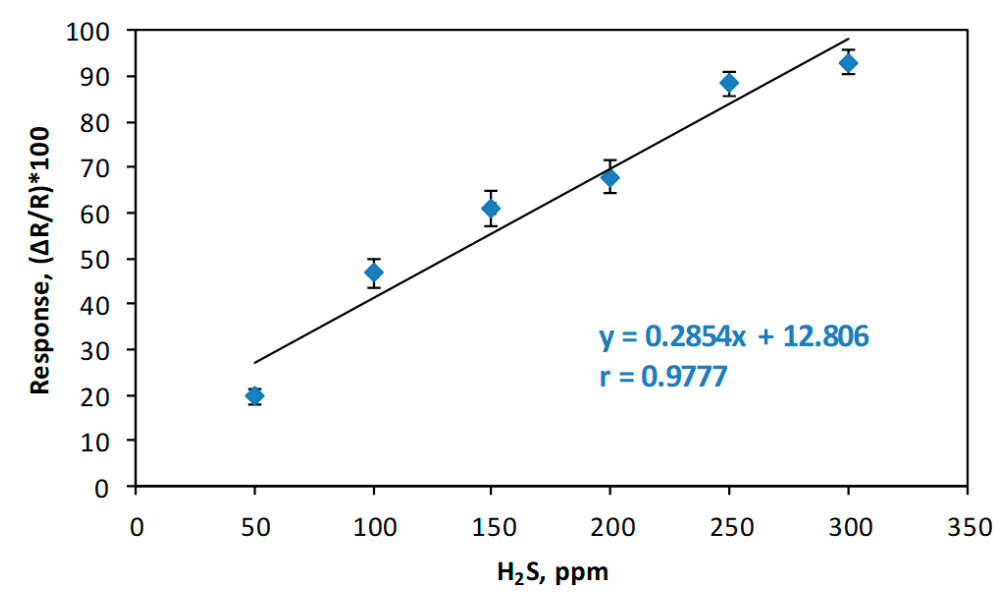

(a)

Figure 6. Cont. 


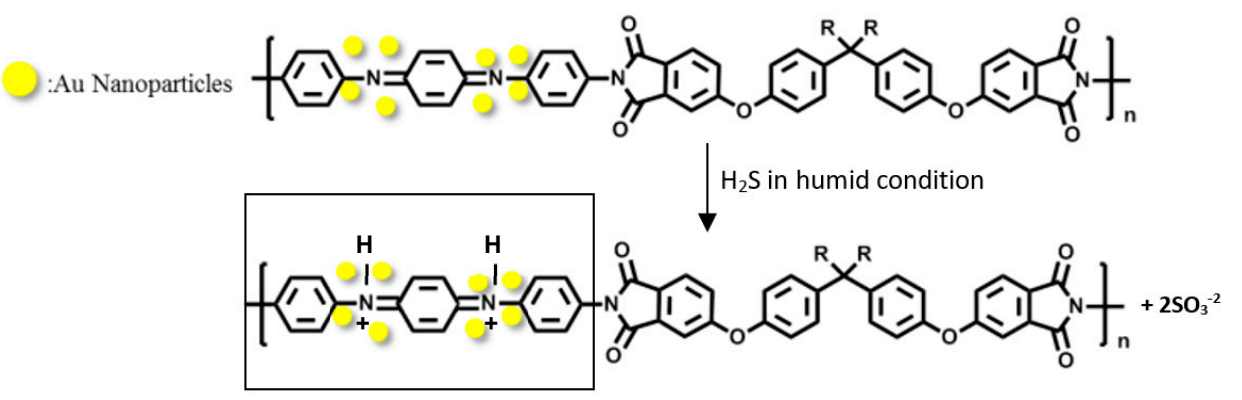

(b)

Figure 6. (a) Calibration plot obtained after the electroactive PI/AuNPs-based chemiresistor sensor was exposed towards increasing concentrations of $\mathrm{H}_{2} \mathrm{~S}$ gas at RT $(\mathrm{n}=3)$; and $(\mathbf{b})$ the proposed sensing mechanism.

As indicated in Figure 6b, the decrease in resistance in the electroactive PI/AuNPs film could possibly be attributed to further doping of the polymer due to the sulfurous acid formed. Hydrogen sulfide gas $\left(K_{\mathrm{a}}=1.1 \times 10^{-7}\right)$ in humid condition may generate sulfurous acid $\left(K_{\mathrm{a}}=1.3 \times 10^{-2}\right)$, which consequently dissociates more effectively into hydrogen and sulfite ions. At room temperature and pressure, the hydrogen ions, then, protonate the polymer's imine nitrogen sites of the ACAT chains. This phenomenon results to a corresponding increase in conductivity or decrease in resistance. Experimental data show that higher concentrations of $\mathrm{H}_{2} \mathrm{~S}$ gas lead to higher decrease in resistance. It is speculated that the resulting positive charges in the imine nitrogen are counteracted by the negatively charged sulfite ions. Furthermore, the gold nanoparticles could possibly be contributing to the stabilization of the interaction by attracting the sulfur-containing counter ions toward the ACAT segments.

Repeatability of the sensor's response. Figure 7a shows a comparison of calibration plots of electroactive PI/AuNPs and PANI/AuNPs chemiresistor sensors towards increasing concentration of hydrogen sulfide gas. The latter has a sensitivity of $0.11 \% \mathrm{ppm}^{-1} \mathrm{H}_{2} \mathrm{~S}$, a theoretical detection limit of $0.45 \mathrm{ppm} \mathrm{H}_{2} \mathrm{~S}$, and a linearity of 0.9551 at the same linear concentration range of 50 to $300 \mathrm{ppm}_{2} \mathrm{~S}$ gas. Based on sensitivity values, there was a $62 \%$ improvement in the performance with electroactive PI/AuNPs sensor. This may be attributed to the formation of additional conducting paths due to further doping of PI's active sites. This, consequently, improved hopping of electrons throughout the polymeric chain.

The repeatability studies depicted in Figure $7 \mathrm{~b}, \mathrm{c}$ prove the better precision of all the trials, with respect to sensitivity values, in electroactive PI/AuNPs ( $\%$ RSD $=8.88 \%$ ) than PANI/AuNPs $(\% \mathrm{RSD}=28.36 \%)$.

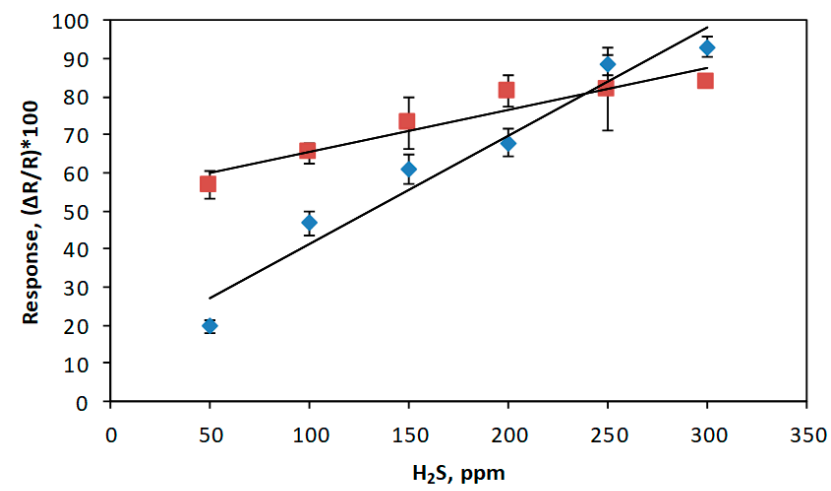

(a)

Figure 7. Cont. 


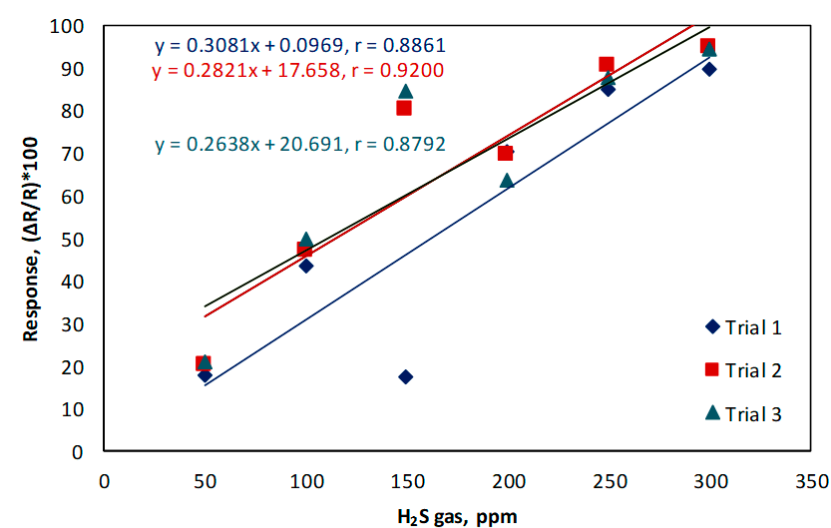

(b)

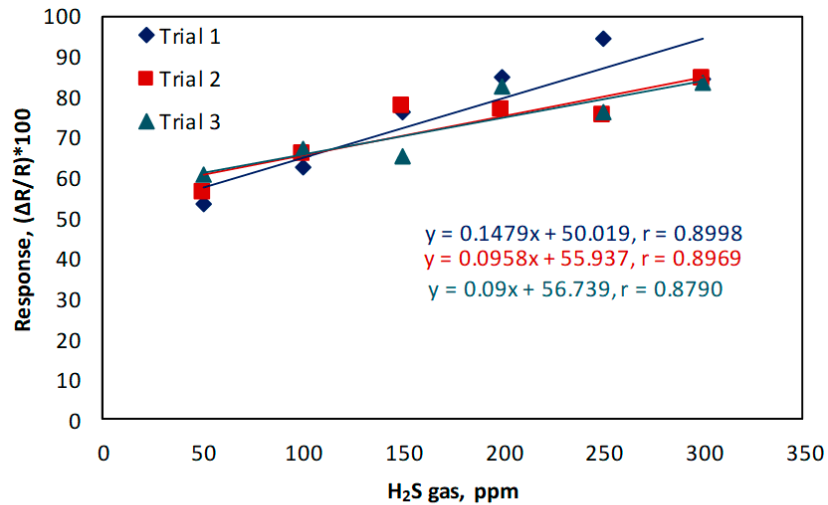

(c)

Figure 7. (a) A comparison of the calibration plots of electroactive PI/AuNPs-, and PANI/AuNPs-based chemiresistor gas sensors towards increasing concentrations of $\mathrm{H}_{2} \mathrm{~S}$ gas (50 to $300 \mathrm{ppm}, \mathrm{n}=3, \mathrm{RT}$ ). Repeatability studies based on the calibration plots of (b) PI/AuNPs, and (c) PANI/AuNPs.

Response and Recovery Characteristics of the Sensor. Response time refers to the duration it takes the sensor to change from its initial state to its stable value, while recovery time is the period it takes the sensor to return to its initial state. As shown in Figure 8, a response time of $43 \mathrm{~s}$ and recovery time of $99 \mathrm{~s}$ was exhibited by PI/AuNPs while a response time of $55 \mathrm{~s}$ and recovery time of $103 \mathrm{~s}$ was shown by the PANI/AuNPs. The faster response time and recovery in PI/AuNPs could be attributed to the polymer's three-dimensional (3D) surface, i.e., the porous sensing membrane contributing to higher surface area (see FE-SEM presented in Figure 4d). This 3D structure, in both PI/AuNPs and PANI/AuNPs, allows easier diffusion of gas analyte into and out of the polymer matrix. Morphological studies revealed that PI/AuNPs are more porous than PANI/AuNPs. This increase in surface area could possibly be the cause of the higher response at a faster gas diffusion rate in PI/AuNPs.

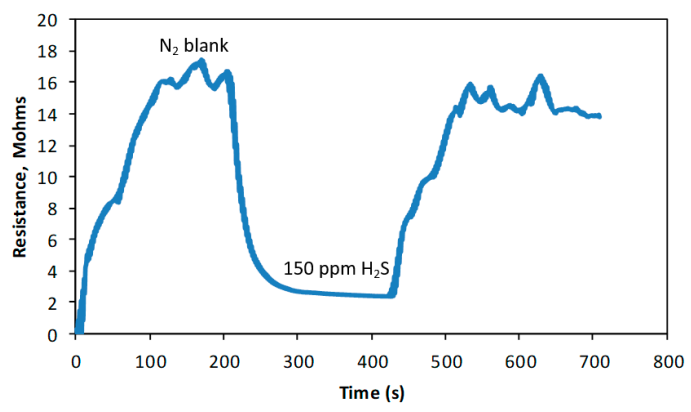

(a)

Figure 8. Cont. 


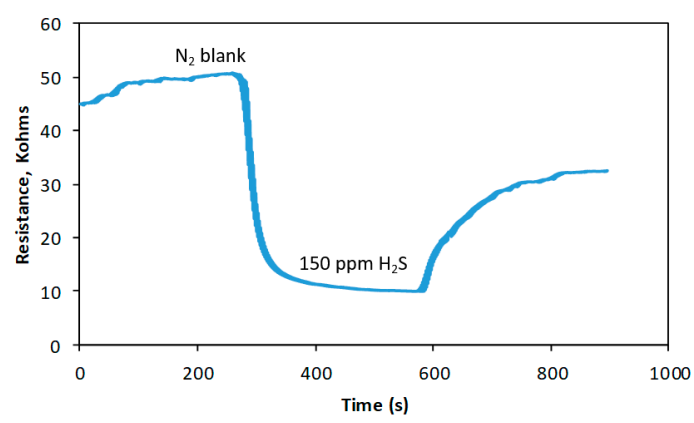

(b)

Figure 8. Dynamic response and recovery characteristics of (a) PI/AuNPs, and (b) PANI/AuNPs-based

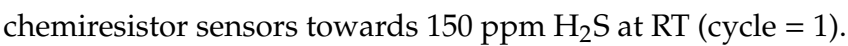

Reversibility of the Sensor's response. As shown in Figure 9a, the PI/AuNPs sensor exhibited a good reversibility within 3 cycles of exposure to alternating $\mathrm{N}_{2}$ blank and $200 \mathrm{ppm} \mathrm{H}_{2} \mathrm{~S}$ (RSD $=8.60 \%$ ). The reading returned to its baseline value once the gas analyte was removed.

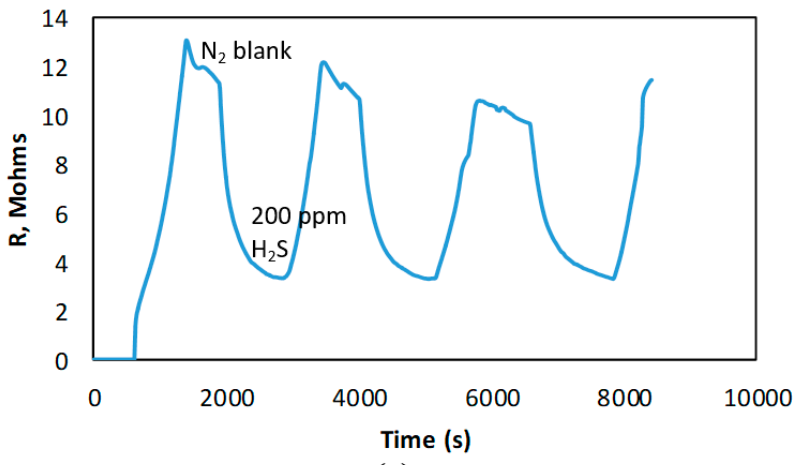

(a)

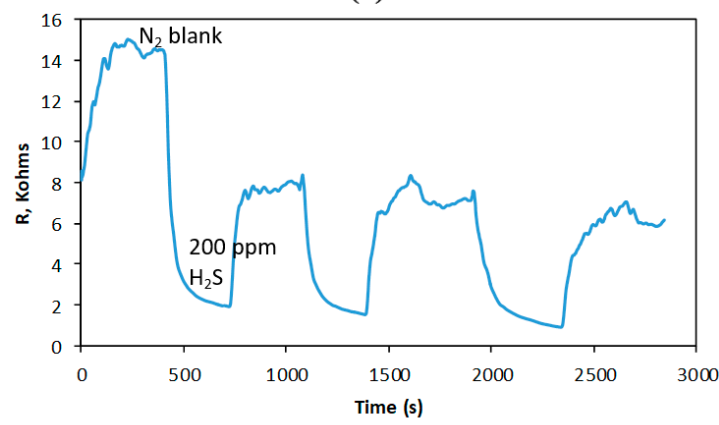

(b)

Figure 9. A comparison of the reversibility of the response of (a) PI/AuNPs, and (b) PANI/AuNPs-based

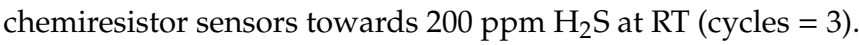

The case is different compared with the performance of PANI/AuNPs sensor. Figure $9 \mathrm{~b}$ shows that the sensor did not exhibit a good reversible process. The sensor experienced difficulty in reverting to the baseline reading after the first cycle of exposure to $\mathrm{H}_{2} \mathrm{~S}$ gas. An RSD of $41.79 \%$ validated that PANI/AuNPs showed a poor reversibility.

Selectivity. The selectivity studies in Figure 10 revealed that the electroactive PI/AuNPs-based chemiresistor sensor resulted in the highest resistance change towards $300 \mathrm{ppm}$ hydrogen sulfide gas compared to minimal to almost negligible response when the sensor was exposed to pure forms of solvents of varying polarity such as hexane, ethyl acetate, and methanol vapors. The same sensor, when exposed and tested towards the same concentration of ammonia gas, resulted in a signal that was opposite in direction, implying a different sensing mechanism. 


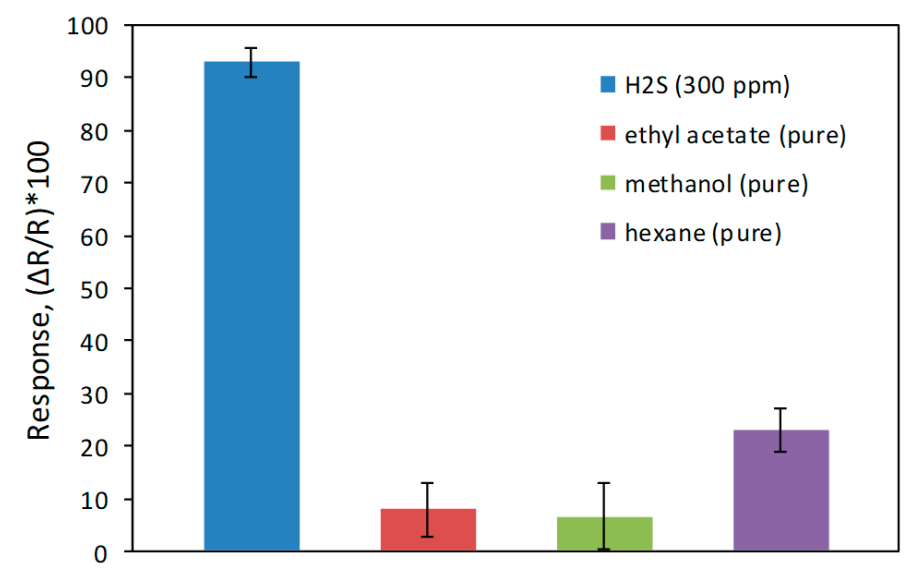

Figure 10. Selectivity test of electroactive PI/AuNPs with $300 \mathrm{ppm}$ concentration of $\mathrm{H}_{2} \mathrm{~S}$, ethyl acetate (pure), methanol (pure), hexane (pure); $(\mathrm{n}=3, \mathrm{RT})$.

\section{Conclusions}

An electroactive polyimide/gold nanoparticles-based chemiresistor sensor that operates at ordinary room temperature was developed. The change in the electrical property, particularly the resistance of the sensing material, was used as a means to monitor the change in $\mathrm{H}_{2} \mathrm{~S}$ gas concentration. Spectral studies confirmed successful synthesis of its sensing material. Morphological studies, on the other hand, confirmed the increase in surface area of electroactive polyimide after decorating it with gold nanoparticles. Compared with the conventional conducting PANI, likewise doped with AuNPs to ensure similar matrix, the electroactive PI/AuNPs exhibited an improved sensing performance. The proposed sensor offers an alternative means of monitoring hydrogen sulfide gas in a simple and inexpensive way.

Author Contributions: J.-M.Y. and K.S.S. conceptualized the project and overall design of the experiment. L.M.G.P. performed the experimental part under the supervision of K.S.S., and both wrote the manuscript. J.-M.Y. and K.S.S. edited and finalized the paper.

Funding: The authors extend their gratitude for the financial assistance provided by the Department of Science and Technology-Philippine Council for Industry, Energy, and Emerging Technology Research and Development (DOST-PCIEERD, through the Manila Economic and Cultural Office-MECO), and University of Santo Tomas-Research Center for the Natural and Applied Sciences; and the Ministry of Science and Technology, Taiwan, R.OSC (MOST 104-2113-M-033-001-MY3 and MOST 104-2923-M-033-001-MY2) as well as the Department of Chemistry at Chung Yuan Christian University.

Conflicts of Interest: The authors declare no conflict of interest.

\section{References}

1. OSHA Fact Sheet; U.S. Department of Labor: Washington, DC, USA. Available online: https://www.osha.gov/ SLTC/hydrogensulfide/hazards.html (accessed on 3 November 2019).

2. Occupational Safety and Health Administration Technical Center. Hydrogen Sulfide Backup Data Report (ID-141); Occupational Safety and Health Administration Technical Center: Salt Lake City, UT, USA, 1989.

3. Rubright, S.; Pearce, L.; Peterson, J. Environmental toxicology of hydrogen sulfide. Nitric Oxide 2017, 71, 1-13. [CrossRef]

4. Guidotti, T.L. Hydrogen Sulfide Intoxication. In Handbook of Clinical Neurology, 3rd ed.; Lotti, M., Bleecker, M.L., Eds.; Elsevier: Amsterdam, The Netherlands, 2015; Chapter 8; Volume 131, pp. 111-133.

5. Roth, S.H. Handbook of Hazardous Materials; Academic Press: Cambridge, UK, 1993; pp. 367-376.

6. Terrence, S. Hydrogen Sulphide in Agricultural Biogas Systems; Ministry of Agriculture Food and Rural Affairs: Centre Wellington, ON, Canada, 2011; pp. 1-7.

7. Plaza, C.; Xu, Q.; Townsend, T.; Bitton, G.; Booth, M. Evaluation of alternative landfill cover soils for attenuating hydrogen sulfide from construction and demolition (C\&D) debris landfills. J. Environ. Manag. $2007,84,314-322$. 
8. Shen, D.S.; Du, Y.; Fang, Y.; Hu, Li.; Fang, Ch.; Long, Yu. Characteristics of H2S emission from aged refuse after excavation exposure. J. Environ. Manag. 2015, 154, 159-165. [CrossRef]

9. Textor, C.; Graf, H.F.; Herzog, M.; Oberhuber, J.M. Injection of gases into the stratosphere by explosive volcanic eruptions. J. Geophys. Res. 2003, 108, 4606. [CrossRef]

10. Oppenheimer, C.; Scaillet, B.; Martin, R.S. Sulfur Degassing from Volcanoes: Source Conditions, Surveillance, Plume Chemistry and Earth System Impacts. Sulfur Magmas Melts 2011, 73, 363-422.

11. Edmonds, M.; Grattan, J.; Michnowicz, S. Volcanic Gases: Silent Killers. In Observing the Volcano World. Advances in Volcanology; Fearnley, C.J., Bird, D.K., Haynes, K., McGuire, W.J., Jolly, G., Eds.; Springer: Cham, Switzerland, 2015.

12. Jafarinejad, S. Odours emission and control in the petroleum refinery: A review. Curr. Sci. Perspect. 2016, 2, 78-82.

13. Jafarinejad, S. Pollutions and Wastes from the Petroleum Industry. In Petroleum Waste Treatment and Pollution Control; Butterworth-Heinemann: Oxford, UK, 2017; pp. 19-83.

14. Shivanthan, M.C.; Perera, H.; Jayasinghe, S.; Karunanayake, P.; Chang, T.; Ruwanpathirana, S.; Jayasinghe, N.; De Silva, Y.; Jayaweerabandara, D. Hydrogen sulphide inhalational toxicity at a petroleum refinery in Sri Lanka: A case series of seven survivors following an industrial accident and a brief review of medical literature. J. Occup. Med. Toxicol. (Lond. UK) 2013, 8, 9. [CrossRef]

15. Kangas, J.; Jappinen, P.; Savolainen, H. Exposure to Hydrogen Sulfide, Mercaptans and Sulfur Dioxide in Pulp Industry. Am. Ind. Hyg. Assoc. J. 1984, 45, 787-790. [CrossRef]

16. Veluchamy, C.; Kalamdhad, A.S. Enhancement of hydrolysis of lignocellulose waste pulp and paper mill sludge through different heating processes on thermal pretreatment. J. Clean. Prod. 2017, 168, 219-226. [CrossRef]

17. Crundwell, F.; Moats, M.; Ramachandran, V.; Robinson, T.; Davenport, W.G. Extractive Metallurgy of Nickel, Cobalt and Platinum Group Metals; Elsevier Ltd.: Oxford, UK, 2011; pp. 443-455. ISBN 9780080968094.

18. Chaulya, S.K.; Prasad, G.M. Chapter 3-Gas Sensors for Underground Mines and Hazardous Areas. In Sensing and Monitoring Technologies for Mines and Hazardous Areas Monitoring and Prediction Technologies; Elsevier: Amsterdam, The Netherlands, 2016; pp. 161-212.

19. Jiang, G.; Keller, J.; Bond, P.L. Determining the long-term effects of H2S concentration, relative humidity and air temperature on concrete sewer corrosion. Water Res. 2014, 65, 157-169. [CrossRef]

20. Andriamanohiarisoamanana, F.J.; Sakamoto, Y.; Yamashiro, T.; Yasui, S.; Iwasaki, M.; Ihara, I.; Tsuji, O.; Umetsu, K. Effects of handling parameters on hydrogen sulfide emission from stored dairy manure. J. Environ. Manag. 2015, 154, 110-116. [CrossRef] [PubMed]

21. Maurer, D.L.; Koziel, J.A.; Bruning, K.; Parker, D.B. Farm-scale testing of soybean peroxidase and calcium peroxide for surficial swine manure treatment and mitigation of odorous VOCs, ammonia and hydrogen sulfide emissions. Atmos. Environ. 2017, 166, 467-478. [CrossRef]

22. Kim, K.H. Performance characterization of the GC/PFPD for H2S, CH3SH, CH3SCH3, and CH3SSCH3 in air. Atmos. Environ. 2005, 39, 2235-2242. [CrossRef]

23. Vitvitsky, V.; Banerjee, R. H2S analysis in biological samples using gas chromatography with sulfur chemiluminescence detection. Methods Enzym. 2015, 554, 111-123.

24. Varlet, V.; Giuliani, N.; Palmiere, C.; Maujean, G.; Augsburger, M. Hydrogen Sulfide Measurement by Headspace-Gas Chromatography-Mass Spectrometry (HS-GC-MS): Application to Gaseous Samples and Gas Dissolved in Muscle. J. Anal. Toxicol. 2015, 39, 52-57. [CrossRef] [PubMed]

25. Larsen, E.S.; Hong, W.W.; Spartz, M.L. Hydrogen Sulfide Detection by UV-Assisted Infrared Spectrometry. Appl. Spectrosc. 1997, 51, 1656-1667. [CrossRef]

26. Chen, R.; Morris, H.R.; Whitmore, P.M. Fast detection of hydrogen sulfide gas in the ppmv range with silver nanoparticle films at ambient conditions. Sens. Actuators B Chem. 2013, 186, 431-438. [CrossRef]

27. Gersen, S.; Van Essen, M.; Visser, P.; Ahmad, M.; Mokhov, A.; Sepman, A.; Alberts, R.; Douma, A.; Levinsky, H. Detection of $\mathrm{H}_{2} \mathrm{~S}, \mathrm{SO}_{2}$ and $\mathrm{NO}_{2}$ in $\mathrm{CO}_{2}$ at pressures ranging from 1-40 bar by using broadband absorption spectroscopy in the UV/VIS range. Energy Procedia 2014, 63, 2570-2582. [CrossRef]

28. Shariati-Rad, M.; Irandoust, M.; Jalilvand, F. Spectrophotometric determination of hydrogen sulfide in environmental samples using sodium 1,2-naphthoquinone-4-sulfonate and response surface methodology. Int. J. Environ. Sci. Technol. 2016, 13, 1347-1356. [CrossRef] 
29. Wallace, K.J.; Cordero, S.R.; Tan, C.P.; Lynch, V.M.; Anslyn, E.V. A colorimetric response to hydrogen sulfide. Sens. Actuators B Chem. 2007, 120,362-367. [CrossRef]

30. Zhang, Y.; Li, M.; Niu, Q.; Gao, P.; Zhang, G.; Dong, C.; Shuang, S. Gold nanoclusters as fluorescent sensors for selective and sensitive hydrogen sulfide detection. Talanta 2017, 171, 143-151. [CrossRef] [PubMed]

31. Lawrence, N.S.; Deo, R.P.; Wang, J. Electrochemical determination of hydrogen sulfide at carbon nanotube modified electrodes. Anal. Chim. Acta 2004, 517, 131-137. [CrossRef]

32. Zeng, L.; He, M.; Yu, H.; Li, D. An $\mathrm{H}_{2}$ S Sensor Based on Electrochemistry for Chicken Coops. Sensors 2016, 16, 1398. [CrossRef]

33. Ke, Z.J.; Tang, D.L.; Lai, X.; Dai, Z.Y.; Zhang, Q. Optical fiber evanescent-wave sensing technology of hydrogen sulfide gas concentration in oil and gas fields. Optik 2018, 157, 1094-1100. [CrossRef]

34. Zhou, H.; Wen, J.Q.; Zhang, X.Z.; Wang, W.; Feng, D.Q.; Wang, Q.; Jia, F. A Study on Fiber-optic Hydrogen Sulfide Gas Sensor. Phys. Procedia 2014, 56, 1102-1106. [CrossRef]

35. He, H.; Dong, C.; Fu, Y.; Han, W.; Zhao, T.; Xing, L.; Xue, X. Self-powered smelling electronic-skin based on the piezo-gas-sensor matrix for real-time monitoring the mining environment. Sens. Actuators B Chem. 2018, 267,392-402. [CrossRef]

36. Kuchmenko, T.A.; Kochetova, Z.Y.; Silina, Y.E.; Korenman, Y.I.; Kulin, L.A.; Lapitski, I.V. Determination of Trace Amounts of Hydrogen Sulfide in a Gas Flow Using a Piezoelectric Detector. J. Anal. Chem. 2007, 62, 781-787. [CrossRef]

37. Berahman, M.; Sheikhi, M. Hydrogen sulfide gas sensor based on decorated zigzag graphene nanoribbon with copper. Sens. Actuators B Chem. 2015, 219, 338-345. [CrossRef]

38. Tomchenko, A.A.; Harmer, G.P.; Marquis, B.T.; Allen, J.W. Semiconducting metal oxide sensor array for the selective detection of combustion gases. Sens. Actuators B Chem. 2003, 93, 126-134. [CrossRef]

39. MalekAlaie, M.; Jahangiri, M.; Rashidi, A.; HaghighiAsl, A.; Izadi, N.; Rashidi, A. Selective hydrogen sulfide $\left(\mathrm{H}_{2} \mathrm{~S}\right)$ sensors based on molybdenum trioxide $\left(\mathrm{MoO}_{3}\right)$ nanoparticle decorated reduced graphene oxide. Mater. Sci. Semicond. Process. 2015, 38, 93-100. [CrossRef]

40. Kaur, M.; Jain, N.; Sharma, K.; Bhattacharya, S.; Roy, M.; Tyagi, A.; Gupta, S.; Yakhmi, J.V. Room-temperature $\mathrm{H}_{2} \mathrm{~S}$ gas sensing at ppb level by single crystal $\mathrm{In}_{2} \mathrm{O}_{3}$ whiskers. Sens. Actuators B Chem. 2008, 133, 456-461. [CrossRef]

41. Alaie, M.M.; Jahangiri, M.; Rashidi, A.; Asl, A.H.; Izadi, N.; Rashidi, A. A novel selective $\mathrm{H}_{2} \mathrm{~S}$ sensor using dodecylamine and ethylenediamine functionalized graphene oxide. J. Ind. Eng. Chem. 2015, 29, 97-103. [CrossRef]

42. Sarfraz, J.; Ihalainen, P.; Määttänen, A.; Peltonen, J.; Linden, M. Printed hydrogen sulfide gas sensor on paper substrate based on polyaniline composite. Thin Solid Film. 2013, 534, 621-628. [CrossRef]

43. Li, M.; Zhou, D.; Zhao, J.; Zheng, Z.; He, J.; Hu, L.; Xia, Z.; Tang, J.; Liu, H. Resistive gas sensors based on colloidal quantum dot (CQD) solids for hydrogen sulfide detection. Sens. Actuators B Chem. 2015, 217, 198-201. [CrossRef]

44. Kumar, V.; Sunny; Rawal, I.; Mishra, V.; Dwivedi, R.; Das, R. Fabrication and characterization of gridded $\mathrm{Pt} / \mathrm{SiO} 2 / \mathrm{Si}$ MOS structure for hydrogen and hydrogen sulphide sensing. Mater. Chem. Phys. 2014, 146, 418-424. [CrossRef]

45. Emelin, E.V.; Nikolaev, I.N. Sensitivity of mos sensors to hydrogen, hydrogen sulfide, and nitrogen dioxide in different gas atmospheres. Meas. Tech. 2006, 49, 524-528. [CrossRef]

46. Crowley, K.; Morrin, A.; Sheperd, R.; Panhuis, M.; Wallace, G.; Smyth, M.; Killard, A. Fabrication of Polyaniline-Based Gas Sensors using Piezoelectric Inkjet and Silkscreen Printing for the Detection of Hydrogen Sulfide. IEEE Sens. J. 2010, 10, 1419-1426. [CrossRef]

47. Liu, C.; Hayashi, K.; Toko, K. Au nanoparticles decorated polyaniline nanofiber sensor for detecting volatile sulfur compounds in expired breath. Sens. Actuators B Chem. 2012, 161, 504-509. [CrossRef]

48. Chen, R.; Whitmore, P.M. Chapter 6: Silver Nanoparticle Films as Hydrogen Sulfide Gas Sensors with Applications in Art Conservation. In The Science and Function of Nanomaterials: From Synthesis to Application; Harper-Leatherman, A.S., Solbrig, C.M., Eds.; ACS Symposium Series; American Chemical Society: Washington, DC, USA, 2014.

49. Yuan, Z.; Lu, F.; Peng, M.; Wang, C.-W.; Tseng, Y.T.; Du, Y.; Cai, N.; Lien, C.W.; Chang, H.T.; He, Y.; et al. Selective Colorimetric Detection of Hydrogen Sulfide Based on Primary Amine-Active Ester Cross-Linking of Gold Nanoparticles. Anal. Chem. 2015, 87, 7267-7273. [CrossRef] 
50. Ji, W.F.; Chu, C.M.; Hsu, S.C.; Lu, Y.D.; Yu, Y.C.; Santiago, K.S.; Yeh, J.M. Synthesis and characterization of organo-soluble aniline oligomer-based electroactive doped with gold nanoparticles, and application to electrochemical sensing of ascorbic acid. Polymers 2017, 128, 218-228. [CrossRef]

51. Vanherck, K.; Vankelecom, I.; Verbiest, T. Improving fluxes of polyimide membranes containing gold nanoparticles by photothermal heating. J. Membr. Sci. 2011, 373, 5-13. [CrossRef]

52. Weng, C.J.; Jhuo, Y.S.; Chen, Y.L.; Feng, C.F.; Chang, C.H.; Chen, S.W.; Yeh, J.M.; Wei, Y. Intrinsically electroactive polyimide microspheres fabricated by electrospraying technology for ascorbic acid detection. J. Mater. Chem. 2011, 21, 15666-15672. [CrossRef]

53. Weng, C.J.; Huang, K.Y.; Jhuo, Y.S.; Chen, Y.L.; Feng, C.F.; Cho-Ming, C.; Yeh, J.M. Controllable Electroactive Polyimide Particles Size Generated by Electrospraying. Polym. Int. 2012, 61, 205-212. [CrossRef]

54. Huang, T.C.; Lin, S.T.; Yeh, L.C.; Chen, C.A.; Huang, H.Y.; Nian, Z.Y.; Chen, H.H.; Yeh, J.M. Aniline pentamer-based electroactive polyimide prepared from oxidation coupling polymerization for electrochemical sensing application. Polymers 2012, 53, 4373-4379. [CrossRef]

55. Huang, T.C.; Yeh, L.C.; Huang, H.Y.; Nian, Z.Y.; Yeh, Y.C.; Chou, Y.C.; Yeh, J.M.; Tsai, M.H. The use of a carbon paste electrode mixed with multiwalled carbon nanotube/electroactive polyimide composites as an electrode for sensing ascorbic acid. Polym. Chem. 2014, 5, 630-637. [CrossRef]

56. Huang, K.Y.; Jhuo, Y.S.; Wu, P.S.; Lin, C.H.; Yu, Y.H.; Yeh, J.M. Electrochemical Studies for the Content of Amine-Capped Aniline Trimers on the Corrosion Protection Effect of as-prepared Electroactive Polyimide Coatings. Eur. Polym. J. 2009, 45, 485-493. [CrossRef]

57. Weng, C.J.; Huang, J.Y.; Huang, K.Y.; Jhuo, Y.S.; Tsai, M.H.; Yeh, J.M. Advanced anticorrosive coatings prepared from electroactive polyimide-TiO2 hybrid nanocomposite materials. Electrochim. Acta 2010, 55, 8430-8438. [CrossRef]

58. Huang, H.Y.; Huang, T.C.; Yeh, T.C.; Tsai, C.Y.; Lai, C.L.; Tsai, M.H.; Yeh, J.M.; Chou, Y.C. Advanced anticorrosive materials prepared from amine-capped aniline trimer-based electroactive polyimide-clay nanocomposite materials with synergistic effects of redox catalytic capability and gas barrier properties. Polymers 2011, 52, 2391-2400. [CrossRef]

59. Huang, T.C.; Yeh, T.C.; Huang, H.Y.; Ji, W.F.; Chou, Y.C.; Hung, W.I.; Yeh, J.M.; Tsai, M.H. Electrochemical Studies on aniline-pentamer-Based Electroactive Polyimide Coating: Corrosion Protection and Electrochromic Properties. Electrochim. Acta 2011, 56, 10151-10158. [CrossRef]

60. Chang, K.C.; Lu, H.I.; Peng, C.W.; Lai, M.C.; Hsu, S.C.; Hsu, M.H.; Tsai, Y.K.; Chang, C.H.; Hung, W.I.; Wei, Y.; et al. Nanocasting Technique to Prepare Lotus-leaf-like Superhydrophobic Electroactive Polyimide as Advanced Anticorrosive Coatings. ACS Appl. Mater. Interfaces 2013, 5, 1460-1467. [CrossRef]

61. Chou, Y.C.; Lee, P.C.; Hsu, T.F.; Huang, W.Y.; Zi-Han, L.; Chuang, C.Y.; Yang, T.I.; Yeh, J.M. Synthesis and anticorrosive properties of electroactive polyimide $/ \mathrm{SiO}_{2}$ composites. Polym. Compos. 2014, 35, 617-625. [CrossRef]

62. Chang, K.C. Advanced anticorrosive coatings prepared from electroactive polyimide/graphene nanocomposites with synergistic effects of redox catalytic capability and gas barrier properties. Express Polym. Lett. 2014, 8, 243-255. [CrossRef]

63. Huang, T.C.; Yeh, L.C.; Lai, G.H.; Huang, B.S.; Yang, T.I.; Hsu, S.C.; Lo, A.Y.; Yeh, J.M. Advanced Superhydrophobic Electroactive Fluorinated Polyimide and Its Application in Anticorrosion Coating. Int. J. Green Energy 2016, 14, 113-120. [CrossRef]

64. Ji, W.F.; Li, C.W.; Yu, S.K.; Chen, P.J.; Chen, H.L.; Chen, R.D.; Chen, B.H.; Hsu, C.L.; Yeh, J.M. Biomimetic electroactive polyimide with rose petal-like surface structure prepared from nanocasting technique for anticorrosive coating application. Express Polym. Lett. 2017, 11, 635-644. [CrossRef]

65. Weng, C.J.; Jhuo, Y.S.; Huang, K.Y.; Feng, C.F.; Yeh, J.M.; Wei, Y.; Tsai, M.H. Mechanically and Thermally Enhanced Intrinsically Dopable Polyimide Membrane with Advanced Gas Separation Capabilities. Macromolecules 2011, 44, 6067-6076. [CrossRef]

66. Weng, C.J.; Jhuo, Y.S.; Chang, C.H.; Feng, C.F.; Peng, C.W.; Dai, C.F.; Yeh, J.M.; Wei, Y. A smart surface prepared using the switchable superhydrophobicity of neat electrospun intrinsically electroactive polyimide fiber mats. Soft Matter 2011, 7, 10313-10318. [CrossRef]

67. Chang, K.C.; Huang, K.Y.; Hsu, C.H.; Ji, W.F.; Lai, M.C.; Hung, W.I.; Chuang, T.L.; Yeh, J.M. Synthesis of ultra-high-strength electroactive polyimide membranes containing oligoaniline in the main chain by thermal imidization reaction. Eur. Polym. J. 2014, 56, 26-32. [CrossRef] 
68. Chang, K.C.; Lu, H.I.; Lai, M.C.; Hsu, C.H.; Hsiao, Y.R.; Huang, K.Y.; Chuang, T.L.; Yeh, J.M.; Liu, W.R. Enhanced Physical Properties of Electroactive Polyimide Nanocomposites by Addition of Graphene Nanosheets. Polym. Int. 2014, 63, 1011-1017. [CrossRef]

69. Jeon, H.; Lee, K. Effect of gold nanoparticle morphology on thermal properties of polyimide nanocomposite films. Colloids Surf. A Physicochem. Eng. Asp. 2019, 579, 123651. [CrossRef]

70. Wei, Y.; Yang, C.; Ding, T. A one-step method to synthesize n,n'-bis(4'-aminopiienyl)- 1,4-quinonenediimine and its derivatives. Tetrahedron Lett. 1996, 37, 731-734. [CrossRef]

71. Krishnamurthy, S.; Esterle, A.; Sharma, N.C.; Sahi, S.V. Yucca-derived synthesis of gold nanomaterial and their catalytic potential. Nanoscale Res. Lett. 2014, 9, 627. [CrossRef]

72. Sneha, K.; Sathishkumar, M.; Kim, S.; Yun, Y.S. Counter ions and temperature incorporated tailoring of biogenic gold nanoparticles. Process. Biochem. 2010, 45, 1450-1458. [CrossRef]

(C) 2019 by the authors. Licensee MDPI, Basel, Switzerland. This article is an open access article distributed under the terms and conditions of the Creative Commons Attribution (CC BY) license (http://creativecommons.org/licenses/by/4.0/). 